\title{
Sobre la literatura juvenil
}

Palabras clave: literatura juvenil, didáctica de la literatura, literatura.

\section{Introducción}

Quien se proponga escribir o hablar sobre la literatura juvenil se verá abocado a la curiosa situación de tener que explicar previamente cuál es en realidad el objeto que va a abordar. (Baumgärtner, 1974: 11)

Muchos años después de esas palabras del crítico Alfred Baumgärtner, hoy -que se editan numerosos libros para adolescentes y jóvenes, que los convierten en best seller con su lectura masiva- el reconocimiento de una literatura juvenil es incuestionable.

Hay, pues, una literatura específicamente dirigida al lector joven, en unos casos como resultado de un cierto "pacto ficcional" que muchos escritores asumen dirigiéndose expresamente a ese lector diferenciado solo por su edad, y en otros casos como consecuencia de criterios editoriales relacionados con la mercadotecnia, ya que, a veces, libros que aparecen en el mercado para el público adolescente o juvenil no fueron escritos pensando en él; históricamente, han existido ejemplos de obras escritas para los adultos que han calado enseguida en los jóvenes, pasando a ser, en un espacio breve de tiempo, lecturas exclusivamente juveniles: Robinson Crusoe de Defoe, Los viajes de Gulliver de Swift, buena parte de la obra de Julio Verne, o Capitanes de arena de Jorge Amado. Lo que sí ha sucedido, en ocasiones, es que cuando la obra se incorpora al 
circuito lector juvenil lo que triunfa es la parte que contiene más aventuras: sería el caso de Gulliver, multieditado para jóvenes en su parte primera, la que narra el viaje de Gulliver a Lilliput: de su lectura quedan las aventuras, no la sátira que Swift hizo de los vicios y defectos de la sociedad y de los gobiernos de la época, como bien explica Escarpit (1971: 108-109).

\section{Los límites cronológicos de la literatura juvenil}

Pero, ¿dónde empezaría y dónde acabaría lo "juvenil”? La adolescencia es una etapa vital cuyo reconocimiento social es reciente: antes del fin de la $2^{\text {a }}$ Guerra Mundial se pasaba de la infancia a la juventud directamente, porque el inicio de la edad laboral era muy temprano; incluso, educativamente, en muchos países no se ha reconocido la adolescencia hasta que no se ha extendido la educación obligatoria a una edad más avanzada (Lluch, 2003: 35).

En 1985, la Asamblea General de Naciones Unidas definió a los jóvenes como «las personas entre los 15 y 24 años de edad»; desde entonces, las estadísticas de ese organismo se basan en esa definición. Pero, ¿consideramos niños a los menores de 15 años? Es curioso observar que el artículo 1 de la Convención de Naciones Unidas sobre los Derechos del Niño lo define como «persona hasta los 18 años», existiendo, por tanto, unos años (de los 15 y los 18) en que las personas son niños y jóvenes al tiempo, algo paradójico, sin duda. La edad de los jóvenes puede variar de un país a otro, dependiendo de factores socioculturales, económicos o políticos; por eso, hoy se admite la distinción entre adolescentes y jóvenes en una franja de edad que está, según los casos, entre 12 y 18 años, más o menos.

Según Piaget (1975: 96-130), a partir de los 12 años las personas adquieren gradualmente la personalidad (momentos de la adulación del yo y del primer sentimentalismo, de la audacia, la aventura y el pandillaje), y acceden a un estadio del desarrollo cognitivo y psicológico que presupone capacidad para enfrentarse con la realidad circundante, pero también para la abstracción, resolver operaciones formales y formular hipótesis, al margen de la experiencia directa con la realidad. Solo superada esa fase, que dura casi siempre hasta los 14 o 15 años, las personas acceden al estadio de la maduración que les permitirá el inicio de la lectura plena (Cerrillo y Yubero, 2007: 289); ahí podríamos situar el paso de la adolescencia a la juventud, lo que en literatura sería la fase estético literaria, el completo desarrollo lector. Como dicen Bettelheim y Zelan (1982: 37): 
Cuando empezamos a responder personalmente al contenido del texto y a abrirnos a su mensaje (independientemente de si la consecuencia de esto es su aceptación, modificación o rechazo) vamos más allá de una mera descodificación... y empezamos a percibir los significados (...) Nos estamos metiendo activamente en la lectura hasta que al fin somos capaces de comprender lo que el texto significa para nosotros.

En cualquier caso, es un periodo de grandes cambios, lo que Gil Calvo llama "transiciones", es decir cambios transitorios que se suceden en un espacio de tiempo relativamente corto:

Cambios de edad: infancia, adolescencia, primera juventud, madurez adulta... Cambios de nivel de estudios: escuela, instituto, universidad... Cambios de estatus laboral: búsqueda del primer empleo, trabajos iniciales, ascenso en la carrera profesional... Cambios amorosos: primeras relaciones, noviazgo, emparejamiento... Cambios domésticos: salida de casa, vivienda compartida, domicilio propio... (Gil Calvo, 2010: 24)

El lector joven necesita acercarse a la lectura desde posiciones diferentes a las del niño: la posibilidad de enfrentarse a la lectura de obras más complejas le exigirán una lectura de más esfuerzo, que está relacionado con el dominio expresivo y comprensivo de la lengua y con el desarrollo de su competencia lectora. Este asunto genera controversia, sobre todo en los momentos en que se eligen los corpus escolares de lecturas para adolescentes y jóvenes, momentos en que se enfrentan dos tendencias que se sitúan en polos opuestos: el de ganar lectores o, al menos, no perderlos, eligiendo libros de fácil lectura y rápida empatía, por un lado; y el que defiende la necesidad de no renunciar a que, a esas edades, se lean los clásicos, por muy difícil que resulte su lectura (Cerrillo y Sánchez, 2006: 16).

Los jóvenes debieran enfrentarse a la lectura de textos, de contrastada calidad literaria, que propongan "desafíos" lingüísticos (comprensivos e interpretativos), de modo que la lectura resulte estimulante: textos que puedan despertar emociones, plantear preguntas, proponer retos intelectuales, aportar nuevos conocimientos y ayudarles a recorrer su itinerario de lectores competentes y literarios. En cualquier caso, es muy importante que las primeras lecturas de la adolescencia no sean superficiales y demasiado fáciles, porque eso dificultará el paso a otras lecturas, ya no diferenciadas por la edad de sus destinatarios. 


\section{La literatura juvenil como literatura periférica}

De acuerdo a la Teoría de los Polisistemas de Even-Zohar (1978), la literatura juvenil sería una literatura periférica al dirigirse expresamente a lectores de una edad determinada; pero también es cierto que se trata de una literatura con una cierta independencia literaria, a diferencia de la literatura infantil, ya que en la juvenil el mediador adulto no tiene ni la importancia ni la influencia que tiene en la infantil, incluso ese adulto puede no intervenir en la tarea mediadora, aunque sí es un adulto quien escribe para esos lectores. A cambio, en la literatura juvenil sí influyen los "grupos", pues se crean estilos o modas (sagas, series, trilogías) que se imponen en algunos colectivos durante cierto tiempo. En este sentido, podríamos afirmar que la edad de los lectores adolescentes y primeros jóvenes les lleva a reaccionar contra o frente al mundo de los adultos, por un lado, y al mundo de los niños, por otro. Además, como literatura periférica, la literatura juvenil es más susceptible de recibir influencias externas, de experimentar frecuentes cambios o de incorporar modas -casi siempre efímeras-, ya que los gustos o intereses de sus lectores varían con rapidez. La escritora brasileña Marina Colasanti se ha referido a los problemas que pueden encontrarse los escritores que se dirigen a los jóvenes ante los interrogantes que plantea el tiempo de la adolescencia:

El público joven es para él [se refiere al escritor] un blanco altamente improbable. No está, como el [público] de los niños, reunido en un bloque socialmente delimitado y cronológicamente similar. Sus conocimientos no pueden medirse por la edad. El adolescente es una criatura de dos cabezas, oficialmente autorizado a ser adulto y niño al mismo tiempo. (Colasanti, 2008: 164)

Ahí está, quizá, la dificultad que entraña el establecimiento de límites cronológicos inamovibles de inicio y de final de la adolescencia o de inicio de la juventud, momentos en que conviven una fuerte individualidad y un deseo -a veces convulso- de formar parte de algún colectivo. Por eso, el calificativo "juvenil" debemos referirlo a quienes están formando su itinerario lector, que puede coincidir, o no, con las edades a que solemos reducir esas etapas, entre otras razones porque a la misma edad dos personas pueden ofrecer niveles de maduración o intereses diferentes (a veces, a consecuencia del entorno en que viven).

Hoy, la existencia específica de una literatura juvenil está condicionada por el mercado editorial que, como otros mercados (ropa, música, actividades de ocio), 
se dirige expresamente a ellos, pues ve en los jóvenes a potenciales clientes, ya que son un sector de la población con cierta independencia para adquirir sus propios productos. Y, en relación con ese mercado, muchos docentes de Secundaria y Bachillerato buscan libros que empaticen con sus alumnos, una vez que se han dado cuenta que la lectura de los clásicos, como se hacía antaño $-\mathrm{y}$, a veces, aún hoy-, plantea algunos problemas con sus estudiantes (Cerrillo, 2013: 87-106).

Aunque la literatura juvenil se podría considerar una literatura casi adulta -lo es en el abordaje de temas y en sus rasgos de estilo, y sus "circuitos literarios" se aproximan a los de la literatura para adultos, como bien señala Lluch (2003 b: 26-33), no obstante estudios comparatistas nos permiten percibir en ella algunas características distintivas: frecuencia de protagonistas jóvenes, acciones grupales y ambientes juveniles; los personajes adultos intervinientes suelen tener dificultades o sufrir problemas; complicidad con los más desfavorecidos; un notable interés por temas actuales; y una cierta preferencia por las aventuras, la fantasía y el amor, aunque no es desdeñable la corriente realista que acerca a los jóvenes a sus conflictos intergeneracionales, sus choques con la realidad o sus problemas específicos, de la que tenemos buenos ejemplos en diversas obras desde hace cincuenta años: Orzowei (publicada en 1963) de Alberto Manzi, The outsiders (1967) de Susan E. Hinton; o, más recientemente Días de Reyes Magos (1999) de Emilio Pascual, Mágico sur (2005) de Manuel Peña, Tony (2010) de Cecilia Velasco, o La nocbe del polizón (2012) de Andrea Ferrari.

\section{Mercado, corrientes y tendencias de la literatura juvenil}

El mercado del libro juvenil es muy cambiante: las modas, como en otras cosas, marcan las tendencias de la literatura que se edita para jóvenes, finalizando con la misma facilidad con que aparecen. Si antaño la moda fueron las novelas "rosa" para chicas y "de vaqueros" para chicos, hace unos años fueron los relatos de terror y pesadillas, y hoy es una literatura fantástica que, a veces, recuerda parte del mundo de los cuentos maravillosos, que no están, precisamente, en el recorrido lector del público joven, sino bastante tiempo antes.

En general, es frecuente en la literatura juvenil el libro best seller, en donde son perceptibles ciertas características que hacen que esta literatura sea, en más ocasiones de las deseables, repetitiva y predecible: Lluch (2003 b: 47-85) se refiere, entre otras, a la organización lineal del discurso, al uso de un lenguaje simplista, impreciso y, a veces, ilógico, o a la escritura de las historias pensando en su continuidad como sagas o series; a ellas, habría que añadir la notable 
presencia de protagonistas en las mismas edades que los potenciales lectores, que frecuentan los mismos ambientes y que sufren parecidos problemas. Las editoriales que lanzan colecciones específicas para lectores adolescentes y jóvenes buscan así una rápida identificación con ellos, lo que no tendría que ser ni bueno ni malo; lo que sucede es que, con el fin de ser leídos por ese público joven, a veces algunos escritores, y más algunos editores, prefieren libros sencillos, incluso repetitivos, a libros más elaborados, pues así están convencidos de vender más ejemplares.

No obstante, en la literatura juvenil actual (sobre todo en narrativa -la poesía exige un tratamiento diferenciado-) se pueden percibir diversas corrientes ${ }^{1}$ que, en ocasiones, se convierten en tendencias durante un cierto tiempo, siendo las principales el realismo y la fantasía:

1. Realismo. Relatos en los que se tratan problemas o asuntos de la vida cotidiana de los jóvenes y de sus familias (anorexia, inmigración, amor, discriminación, acoso, terrorismo, maltrato): El cazador de estrellas (Ricardo Gómez), Los años terribles (Yolanda Reyes), OK, mister Foster (Eliacer Cansino), Uma vontade louca (Ana $M^{\mathrm{a}}$ Machado), Toby (Graciela Cabal), Mai (Hilda Perera), Yo soy mayor que mi padre (Pedro Sorela), Stéfano ( $M^{\mathrm{a}}$ Teresa Andruetto), Óyeme con los ojos (Gloria C. Díaz) o El anillo de Irina (Care Santos). A esta tendencia realista pertenece la narrativa que asume compromiso ideológico, casi siempre referido a conflictos bélicos o a represiones y persecuciones en sistemas dictatoriales: Silencio en el corazón (de Jaume Cela), El golpe y los cbicos (de Graciela Montes) o Los sapos de la memoria (de Graciela Bialet).

Es imprescindible destacar el precedente de El guardián entre el centeno, de J. D. Salinger, cuya aparición en 1951 provocó un verdadero impacto en la sociedad estadounidense, convirtiéndose enseguida en un verdadero clásico contemporáneo de la literatura juvenil universal. El adolescente protagonista, Holden Caulfield, en el Nueva York de mediados de los cuarenta del pasado siglo, vive la realidad de un muchacho que, con sus pocos años, tiene que enfrentarse al fracaso escolar y al cambio de la infancia a la adolescencia (con todo lo que conlleva), en el seno de una familia conservadora como la suya. Probablemente a partir de la publicación de este libro la literatura juvenil se desprendió de los corsés que impedían que en ella se trataran ciertos temas.

2. Fantasía. Su proliferación en los últimos años, a raíz del éxito de la serie de Harry Potter y la reedición de El señor de los anillos, ha provocado que el

$1 \quad$ Los libros citados lo son a título de ejemplos de cada una de las corrientes señaladas. 
mercado editorial haya visto en esta literatura un filón casi inagotable, existiendo ejemplos de todo tipo, casi siempre presentados en formatos de sagas o series, de gran éxito entre adolescentes y jóvenes: Crepúsculo (Stephenie Meyer), Memorias de Idbun (Laura Gallego) o Juego de tronos (George R. Martin). Incluso hay novelas que tienden a innovar en el género: La séptima expedición al Malabí de Gabriel Sáez, o Loba de Verónica Murguía, galardonada con el Premio Gran Angular en 2013.

Algunas, como Crepúsculo, dejan ver referencias a géneros distintos, lo que estaría relacionado con la activación del intertexto lector de los jóvenes, algo que el escritor sabe que puede atraer a su libro a un público familiarizado con esos diferentes géneros: «El éxito de la tetralogía de Meyer [Crepúsculo] activa un universo de ficción que aunque nace en el siglo XIX, principalmente con la obra de Bram Stocker, Drácula, se introduce en el consumo juvenil con series como Buffy, la cazavampiros [...]» (Lluch, 2010: 119).

A veces, utilizando criterios reduccionistas, con la intención de menospreciarla, se relega esta tendencia a la literatura juvenil, olvidando que, históricamente, existe una importante tradición de literatura fantástica en las novelas de caballerías de los siglos XV y XVI; o, más recientemente -aunque solo en cierta manera-, en algunas novelas de J. Cortázar o J. L. Borges; incluso, hay antecedentes muy valiosos en la propia literatura infantil (El maravilloso mago de $O z$ de L. Frank Baum).

Habría que preguntarse la razón por la que esta literatura, ciertamente más comercial, tiene hoy tanta fuerza entre el público lector adolescente: quizá porque ayuda a "leer el mundo" de manera más abierta, es decir, con más posibilidades interpretativas; o, quizá también, porque es una literatura a la que el lector accede directamente, por decisión propia, sin necesidad de la mediación de un adulto que le sugiera, recomiende o elija la lectura.

Seguramente la saga de Harry Potter no pasará a formar parte del canon literario juvenil pero sí que ocupará un capítulo en los estudios de la sociología de la lectura o de la literatura. Los siete libros de Rowling consiguieron dar el salto cualitativo que las lecturas para niños y jóvenes habían iniciado años antes: pasar de la escuela (o de la biblioteca) al mercado. O dicho en términos políticamente correctos, dejar que el autor y la editorial hablaran directamente al lector, liberando parte de esta comunicación de la tutela del mediador. (Lluch, 2010: 105) 
Junto al realismo y a la fantasía, otras tendencias destacables, en menor medida, son:

3. Aventuras. Esta narrativa, que siempre había tenido un público lector adulto, pasó a ser lectura juvenil en el siglo XIX, primero en la Inglaterra victoriana y luego con la obra del francés Julio Verne; el precedente está en el siglo XVIII con el Robinson Crusoe de Defoe. La narrativa de aventuras se ha caracterizado por la frecuencia con que se dan una serie de rasgos: protagonistas adolescentes que hablan en primera persona; recorridos iniciáticos que conducen a lugares exóticos o, al menos, ajenos a la realidad de la que se parte; expresión casi lineal con poco aparato estilístico; estructura secuenciada en capítulos; presencia de riesgos; o tendencia a finales positivos.

Stevenson, Kipling, Twain, Burroughs o London son autores cuyas obras ocupan lugares destacados entre los lectores de esta narrativa de todo el mundo, en la que, más recientemente, podríamos incluir novelas como Las aventuras de Kid Parvatti (Miguel Larrea), Mágico sur (Manuel Peña), Una semana en Lugano (Francisco Hinojosa) o La leyenda del rey errante (Laura Gallego). Los jóvenes siempre se han sentido atraídos por la vida en lugares diferentes o en tiempos desconocidos, así como por las aventuras que les ayudan a escapar de la cotidianeidad; si antes fue la aventura impensable de las historias de Verne, hoy lo es la aventura insólita de Harry Potter.

4. Historia. Esta narrativa se suele ambientar en el pasado medieval o en escenarios de culturas lejanas, tratando asuntos o acontecimientos históricos de relevancia y significación para la historia de la humanidad. Serían buenos ejemplos El oro de los sueños (José Ma Merino), La catedral (César Mallorquí), La espada y la rosa (Martínez Menchén), Oro de Indias (Carlos Villanes) o Finis Mundi (Laura Gallego).

5. Amor. Suelen ser novelas con argumentos románticos y protagonistas adolescentes, como el público al que se dirigen. El éxito de esta tendencia, que cobra fuerza a principios del siglo XXI, está bastante ligado al aumento de las webs y los blogs sobre lecturas juveniles que, en muchos casos, realizan los propios lectores. El círculo de fuego y Guardianes del Tiempo (Marianne Curley) y, un poco más tarde, Crepúsculo (Stephenie Meyer), aunque esta con elementos fantásticos, son la avanzadilla de un camino muy prolífico en todo el mundo, que no sabemos lo que durará. Sí es cierto que las editoriales han encontrado en estas novelas para adolescentes un público lector al que intentan fidelizar con continuas novedades (El club de los corazones solitarios 
de Elizabeth Eulberg, o ¡Buenos días, princesa! de Blue Jeans); o con campanas de marketing muy bien pensadas, como la titulada "Enamocciate" para leer a Federico Moccia. Al margen del "best seller", hay también novelas juveniles de tema amoroso: Clase de inglés (Lygia Bojunga) o La estrella de la mañana (Jordi Sierra i Fabra), son dos ejemplos.

Junto a todo ello, también hay narrativa juvenil de terror (;Socorro! Doce cuentos para caerse de miedo de Elsa Bornemann), novela policíaca (Flanagan Blues Band de Andreu Martín), microrrelato y relato corto (Temporada de fantasmas de Ana $M^{a}$ Shua), o ciencia ficción (Lo único del mundo de Ricardo Mariño).

Lluch (1999: 24-27) explica muy bien cómo la literatura juvenil más comercial suele proponer un "lector modelo", que se identifica con el lector real, siendo ese uno de los factores principales de la empatía que tienen esos libros -casi siempre relatos- con los lectores a quienes se dirigen. Ese "lector modelo" condiciona de algún modo la producción editorial, pues la fidelización de adolescentes y jóvenes es un rasgo que las editoriales buscan en colecciones y series. Lo que sucede es que, según la teoría lingüística de la Estética de la recepción, (Fokkema e Ibsch, 1977: 108) ese "lector modelo" también condiciona la recepción de la obra literaria, pues los lectores adolescentes, al ser un público lector en formación, reciben textos según sea su competencia lingüística y según estén desarrollados sus valores, sus ideas y, sobre todo, su intertexto lector y su capacidad para la ficción.

El estudio de la literatura juvenil requiere tres niveles de análisis (Lluch, 2003a: 37): el análisis del contexto (tanto social como histórico y literario), el de los paratextos editoriales (mucho más importantes en la literatura infantil y juvenil que en la dirigida a los adultos) y el de la propia narración (análisis que atenderá a tiempo y espacio de la acción, personajes intervinientes, voz del narrador, estructura narrativa, recursos de estilo). No debemos minusvalorar el primero de esos análisis, el que suele pasar más desapercibido, porque su importancia es tan grande que puede determinar la diferente posición de dos lectores ante una misma historia: si no contextualizamos Robinson Crusoe de Defoe (editado en 1719) leeremos la historia de aventuras que vive un náufrago inglés, durante 28 años, en una remota isla en la desembocadura del Orinoco; pero si la contextualizamos, leeremos el pensamiento de un hombre de su época por medio de largas y tediosas reflexiones filosóficas. 


\section{De literatura a literatura}

Hay libros de literatura juvenil que pueden ser un buen camino para que los adolescentes lleguen a la lectura de otros libros, también los clásicos. Es el caso de las novelas iniciáticas Días de Reyes Magos de Emilio Pascual (1999) y El libro salvaje de Juan Villoro (2008).

Días de Reyes Magos es el relato en primera persona de un chico que a los dieciséis años decidió marcharse de su casa, por razones más o menos comprensibles; la decisión la aplazó ante la sugerencia de una buena amiga: de ese modo, irá por casa de sus padres solo lo necesario, dedicando la mayor parte del tiempo a caminar con total autonomía. Lo que sucede es que, desde el momento en que su vida cambia del modo indicado, al chico le empiezan a pasar cosas extrañas, pero interesantes: cierto día se da cuenta de que su padre ya no vive en su casa, o le dejan en el buzón misteriosos libros que suelen tener algún significado oculto o, sobre todo, encuentra un sorprendente trabajo: lector de un ciego, es decir "lazarillo" lector. Mediante esta trama, Pascual construye una historia iniciática, con la literatura como material imprescindible. El protagonista dice al principio que en la biblioteca familiar él solo había elegido El Principito, del que afirma que «nunca supe hurtarme a la fascinación que en mí ejercía» (Pascual, 2007: 14). Pero, luego, van apareciendo títulos emblemáticos de la literatura universal: Quijote, El viejo y el mar, La isla del tesoro, Los viajes de Gulliver, Las aventuras de Tom Sawyer, Hamlet, Huckleberry Finn o el Lazarillo de Tormes.

La fascinación de la literatura es parte esencial de esta entrañable historia de inicio a la vida de lector, del paso de niño a adolescente y adulto. Lo que sucede es que si, como dice Mendoza (2001: 97) «El intertexto lector permite que el lector perciba las relaciones entre una obra y otras que la han precedido, de modo que le ayuda a construir, con coherencia, el significado de un texto», eso solo se cumplirá en el lector de Días de Reyes Magos si ya es un buen lector, pues el autor cita gran cantidad de obras y hace continuas referencias literarias². La novela es un homenaje a la literatura, a libros clásicos de todos los tiempos y de todos los públicos, y a muchas de las mejores novelas de aventuras; es un libro de libros que activará el intertexto lector de los lectores adolescentes y que, quizá, acercará a la literatura a quienes no son lectores habituales, conduciéndoles de una lectura a otras lecturas.

2 Como es necesario que el lector de Días de Reyes Magos posea un amplio bagaje de lecturas literarias, algo que es difícil que tengan los lectores adolescentes destinatarios del libro, el autor, Emilio Pascual (2007), preparó una edición posterior con notas a pie de página, en las que explica las citas y referencias que incluye en su historia. 
En El libro salvaje Juan Villoro reflexiona sobre la lectura y sobre la condición de lector en el contexto de la historia que ha creado, además de proporcionar claves para acercarse a libros clásicos que pudieran formar parte del itinerario lector de los jóvenes que a él acudan.

La novela narra la historia de Juanito, adolescente de padres separados, que va a vivir con tío Tito, bibliófilo empedernido, en cuya casa solo hay libros y un viejo teléfono que no suele funcionar. Tío y sobrino vivirán una relación de amor por los libros: el tío se dará cuenta que Juanito es un "lector prínceps" con un gran potencial por explotar, al que encargará la tarea especial de buscar "el libro que nunca se ha podido leer", El libro salvaje; la búsqueda proporcionará al chico el descubrimiento de historias que esperan lectores, porque los libros buscan a quienes quieran leerlos.

En El libro salvaje es perceptible un proceso transaccional entre lector y texto, por medio del que se establece una relación recíproca entre ambos. El lector del libro se acerca al texto con expectativas que le conducirán a nuevas lecturas desde la activación de experiencias lectoras previas. En cualquier proceso transaccional son fundamentales lector y texto: el autor busca lectores cómplices, quizá por eso Villoro se dirige expresamente a los jóvenes, porque es un público con tendencia a la complicidad, es decir a la participación directa en la historia creada por él, que es a lo que invita El libro salvaje, a participar en el juego de la lectura, a despertar la capacidad de relacionar ese libro con otros libros, a activar el intertexto lector de quien lo está leyendo (Mendoza, 2001: 141-158), porque en él el tío de Juanito evoca autores y libros de cuya lectura "vale la pena alimentarse" citando, entre otros, a Borges, Cortázar, Conan Doyle, Homero, Kafka o Aristófanes.

\section{Literatura juvenil y didáctica de la literatura. El ejemplo del Capitán Alatriste}

Cuando Carlota, la hija del novelista Arturo Pérez Reverte, estaba a punto de iniciar el Bachillerato, su padre se dio cuenta que, hasta entonces, los libros de texto de la chica solo dedicaban una página al Siglo de Oro, un periodo fundamental de la historia y la literatura españolas, de enorme proyección en casi todo el mundo. Pérez Reverte pensó de qué manera atractiva podía enseñar a su hija algo más de aquel periodo tan importante: así concibió la escritura de la novela El Capitán Alatriste, ambientada en aquellos tiempos y narrada en primera persona por un personaje de la misma edad que su hija -el 
paje y escudero Íñigo de Balboa-, y de la que Carlota sería, precisamente, la documentalista.

Es fácil percibir, por tanto, una cierta intención didáctica en el autor. El objetivo de interesar a una adolescente en el estudio del Siglo de Oro español es asumible con la lectura de cualquiera de las novelas que protagoniza Alatriste (a caballo entre la historia y las aventuras), al tiempo que es una buena manera de enseñar literatura más allá de planteamientos exclusivamente historicistas. Hoy, la enseñanza de la literatura debiera incorporar nuevos planteamientos metodológicos, en los que la experiencia personal de la lectura y la posición del lector debieran tenerse en cuenta, para lo que se necesita una mayor implicación del alumno en el proceso de enseñanza/aprendizaje, que se concrete en un mayor trabajo autónomo, individual y grupal; y también el planteamiento de objetivos que atiendan no solo a la adquisición de conocimientos, sino también a la asunción de actitudes relacionadas con la historia, el contexto y la vida cotidiana de la época en que la obra literaria fue escrita. Con la lectura del Capitán Alatriste, la primera de las novelas de la serie, podríamos acercar a los adolescentes (estudiantes de Secundaria y Bachillerato) a la comprensión del Barroco español'3. Veamos por qué.

El Capitán Alatriste está ambientada en la época de Felipe IV (1621-1665), es decir en la plenitud del Barroco artístico, en plena decadencia del imperio español. Eso facilitará el acercamiento a la llamada Edad de Oro, los 150 años de los siglos XVI y XVII, que corresponden al Renacimiento (reinados de Carlos I y Felipe II, siglo XVI) y al Barroco (reinados de Felipe III, Felipe IV y Carlos II, siglo XVII), y a la importancia del momento en que se sitúa la novela, la plenitud del Barroco, que se puede explicar con el texto de Pérez Reverte, atendiendo a dos aspectos: la España de la época y la literatura del momento.

\section{- La España de la época}

Cuando Felipe IV accedió a la corona tenía 16 años, siendo el heredero de un imperio colonizador en el que, entre la metáfora y la soberbia, se decía que "nunca se ponía el sol". España mantenía abiertos varios conflictos, entre ellos

3 Aclararé que no se trata de "instrumentalizar" la lectura de una novela juvenil para enseñar "otras cosas", algo - por desgracia - demasiado frecuente en la lectura escolar o prescriptiva; se trata, al contrario, de acercar a los adolescentes a un periodo de la Historia de España con la lectura de una buena novela que puede empatizar fácilmente con ellos, porque ofrece las aventuras de personajes con vida, una trama dinámica y convincente, un lenguaje rico y una excelente documentación, todo lo cual facilitará su acercamiento posterior a la gran literatura de aquel periodo. 
la Guerra de Flandes (agotando los recursos de que disponía, al tiempo que de la conquistada América venía cada vez menos riqueza); ello, junto a problemas en el devenir interior del reino, provocó en los españoles un sentimiento de pesimismo y derrota que se reflejó no solo en la vida diaria, sino también en la literatura: es lo que identifica al Barroco, el desasosiego y el desequilibrio de un momento que sucede a otro de armonía y equilibrio (el Renacimiento), pero en el que se va a producir una eclosión de manifestaciones artísticas de altísima calidad y trascendencia. En diferentes momentos de la novela podemos leer fragmentos en los que se condensa, de magnífica manera, cómo era aquella España:

Una España todavía temible en el exterior, pero que a pesar de la pompa y el artificio de nuestro joven y simpático rey, de nuestro orgullo nacional y nuestros heroicos hechos de armas, se había echado a dormir confiada en el oro y la plata que traían los galeones de Indias. Pero ese oro y esa plata se perdían en manos de la aristocracia, el funcionariado y el clero, perezosos, maleados e improductivos, y se derrochaban en vanas empresas como mantener la costosa guerra reanudada en Flandes, donde poner una pica, o sea, un nuevo piquero o soldado, costaba un ojo de la cara[...]. Aragoneses y catalanes se escudaban en sus fueros, Portugal seguía sujeto con alfileres, el comercio estaba en manos de extranjeros, las finanzas eran de los banqueros genoveses, y nadie trabajaba salvo los pobres campesinos, esquilmados por los recaudadores de la aristocracia y el rey. (Pérez Reverte, 1996: 65)

Las referencias a algunos estamentos sociales de aquella España pueden ayudar a los profesores a explicar la sociedad del momento, en la que la nobleza, llena de privilegios, hacía gala de vanidad y ambición; los funcionarios eran oscuros; había caballeros que vivían de bronca en bronca, soldados hambrientos, clérigos avaros y lascivos, numerosos picaros y falsos mendigos, campesinos que malvivían trabajando de sol a sol y gentes con oficios viles (como los ganapanes -criados eventuales-o los mozos de silla -que transportaban a los clientes en sillas de mano-).

Madrid era la capital del reino desde el reinado de Felipe II (salvo los años 1601 a 1606 en que Felipe III, por consejo del Duque de Lerma, la había trasladado a Valladolid). En tiempos de Felipe IV, Madrid tenía bien ganada fama de ser la ciudad más sucia del mundo; de ello el lector de Alatriste 
puede darse cuenta: «Era la hora menguada, cerca de la medianoche, cuando los vecinos gritaban 'agua va' y arrojaban inmundicias por las ventanas.» (Pérez Reverte, 1996: 31).

\section{- La literatura del Barroco}

Con la lectura de la novela se puede conocer que los textos literarios más difundidos en aquellos años usaban como soporte «Gacetas y hojas sueltas con versos satíricos y anónimos que corrían por la Corte en aquel tiempo a la vez magnífico, decadente, funesto y genial, poniendo como sotana de dómine al valido, a la monarquía, al lucero del alba...» (Pérez Reverte, 1996: 53). Maestro de esa escritura fue Quevedo, personaje de la novela, lo que ayudará al profesor para enfrentar al joven lector a sus textos, o a la polémica literaria de los estilos del Barroco, "conceptismo" y "culteranismo", que provocó la enemistad entre Quevedo y Góngora. Con la novela, el lector atento también se acercará a la comprensión del mundo del teatro del Barroco, en donde literatura y espectáculo se unían, y en el que Lope de Vega lucía con brillo propio:

La España de Felipe IV amó con locura el teatro [...]. Las comedias tenían tres jornadas o actos, y eran todas en verso, con diferentes metros y rimas. Sus autores consagrados eran queridos y respetados por la gente; y la popularidad de actores y actrices era inmensa. Cada estreno o reposición de una obra famosa congregaba al pueblo y la corte, teniéndolos en suspenso, admirados, las casi tres horas que duraba cada representación; que en aquel tiempo solía desarrollarse a la luz del día, por la tarde después de comer, en locales al aire libre conocidos como corrales. (Pérez Reverte, 1996: 191-192).

La lectura de las novelas de Alatriste, bien guiada, puede enseñar literatura. Y "educar" culturalmente desde ella, proponiendo otras actividades (visionado de pinturas o búsqueda de detalles de los escenarios teatrales de la época), y también otras lecturas: del Capitán Alatriste a otras novelas de la misma serie, o a poemas de Quevedo y Góngora, o a comedias de Tirso o Lope. Es uno de los grandes méritos de esta creación de Pérez Reverte que viene a decirnos que la novela juvenil también puede ser lectura prescrita en las aulas de Secundaria o de Bachillerato y que, por medio de ella, los jóvenes podrían acceder en mejores condiciones a la lectura de los clásicos literarios, recorriendo un itinerario lector en que no hubiera propuestas de lecturas que les resulten distantes, difíciles y, en ocasiones, incomprensibles; 
un itinerario en el que los clásicos deben llegar en el momento apropiado. Mientras, la buena literatura juvenil -que existe, sin duda- es necesaria en el itinerario lector de adolescentes y jóvenes.

Muchos de los jóvenes que se mimetizan en sus tribus, cuando están solos se sumergen en la lectura. Y en la lectura se despojan de los distintivos tribales, vuelven a ser simplemente jóvenes miembros de la raza humana, inseguros y llenos de riquezas, avanzando rumbo a sí mismos, adultos en construcción. (Colasanti, 2008: 177)

\section{Bibliografía}

Baumgärtner, A. C. (1974): El libro juvenil alemán boy. Velber: Friedrich Verlag. Bettelheim, B. y Zelan, K. (1982): On learning to read: the child's fascination with meaning. Londres: Thames \& Hudson.

Cerrillo, P. C. (2013): LIJ: Una literatura mayor de edad. Cuenca: Ediciones de la UCLM.

Cerrillo, P. C. y Sánchez, C. (2005): «Literatura con mayúsculas». Ocnos, 2, 7-22.

Cerrillo, P. C. y Yubero, S. (2007): «Qué leer y en qué momento». En: Cerri1lo, P. C. y Yubero, S. (eds.): La formación de mediadores para la promoción de la lectura. Cuenca: Ediciones del CEPLI y Fundación SM, 285-292.

Colasanti, M. (2008): Fragatas para tierras lejanas. México, D.F.: Norma.

Escarpit, R. (1971): Sociología de la literatura. Barcelona: Oikos-Tau.

Even-Zohar, I. (1978): Papers in bistorical Poetics. Tel Aviv: Porter Institute.

Fokkema, D.W. e Ibsch, E. (1977): Teorías de la literatura del siglo XX. (Estructuralismo. Marxismo. Estética de la recepción. Semiótica). Madrid: Cátedra, 1981.

Gil Calvo, E. (2010): «La rueda de la fortuna. Una lectura de la temporalidad juvenil». En: Lluch, G. (ed.): Las lecturas de los jóvenes. Un nuevo lector para un nuevo siglo. Barcelona: Anthropos, 13-38.

Lluch, G. (1999): «La comunicación literaria y el tipo de lector modelo que propone la actual Literatura Infantil». Educación y Biblioteca, 11, 20-27.

Lluch, G. (2003a): «Una propuesta de análisis para la LIJ». CLIJ, 166, 33-40.

Lluch, G. (2003b): Análisis de narrativas infantiles y juveniles. Cuenca: Ediciones de la UCLM. 
Lluch, G. (2010): «Las nuevas lecturas deslocalizadas de la escuela». En: Lluch, G. (ed.): Las lecturas de los jóvenes. Un nuevo lector para un nuevo siglo. Barcelona: Anthropos, 105-128.

Mendoza, A. (2001): El intertexto lector. El espacio de encuentro de las aportaciones del texto con las del lector. Cuenca: Ediciones de la UCLM.

Pascual, E. (2007): Días de Reyes Magos. Madrid: Anaya.

Pérez Reverte, A. (1996): El Capitán Alatriste. Madrid: Alfaguara.

Piaget, J. (1975): Psicología del niño. Madrid: Morata. 
Pedro C. Cerrillo Torremocha

University of Castilla-La Mancha

\section{On children's literature}

Key words: Juvenile literature, Literature didactics, Literature.

There is a literature specifically geared towards juvenile audience, on some occasions as a result of some kind of 'fictional agreement' that many writers take on specifically addressing this audience because of its age. However, in other cases, this is due to the criteria imposed by publishing houses for marketing reasons. Sometimes books marketed for the teenage or juvenile audiences were not intended for them. This paper analyzes the ages boundaries of juvenile literature, its main trends and movements, its link with market and its consideration as peripheral literature. In addition, the author highlights the part juvenile literature plays in literature teaching, exemplified by some books written for teenage or juvenile audiences to encourage them to read. 
Pedro C. Cerrillo Torremocha

Univerza Castilla-La Mancha

\section{O mladinski književnosti}

Ključne besede: mladinska književnost, didaktika književnosti, književnost

Obstaja književnost, ki posebej nagovarja mlado bralstvo; v nekaterih primerih zaradi določenega »fikcijskega pakta«, ki ga številni pisatelji sprejmejo, ko se namenoma usmerijo k bralstvu, ki ga določa zgolj starost; $v$ drugih primerih pa kot posledica s trženjem povezanih založniških zahtev, kajti občasno se na trgu pojavijo knjige, namenjene najstnikom ali mladini, čeprav niso bile napisane zanje. Ta prispevek analizira časovne okvire mladinske književnosti, njene glavne tokove in smeri, njeno povezanost $s$ trgom ter mnenja, da naj bi šlo za obrobno književnost. Avtor poudarja tudi pomen mladinske književnosti pri pouku književnosti, tako da navaja primere iz knjig, napisanih posebej za najstnike in mladino, ki so lahko odlična pot do branja prav vsake knjige, vključno s klasiki. 